\title{
FEATURES OF DISTRIBUTION OF SEISMIC ACTIVITY IN DIFFERENT REGIONS OF EARTH OVER PHASES OF THE 11-YEAR SOLAR CYCLE
}

\author{
V.V. Ruzhich \\ Institute of the Earth's Crust, Siberian Branch of RAS, \\ Irkutsk, Russia,ruzhich@crust.irk.ru
}

\author{
E.A. Levina \\ Institute of the Earth's Crust, Siberian Branch of RAS, \\ Irkutsk, Russia,levina@crust.irk.ru
}

\begin{abstract}
We discuss the relationship of solar activity with the seismicity of Earth and reasons for the differences in the results of studies of various authors. Using the epoch superposition method, we analyze the differences in seismic activity distribution over phases of the 11-year solar cycle for the whole world, hemispheres, sectors, latitudinal belts, and individual regions. The northeastern sector of Earth has been shown to make the main contribution to the planetary distribution of seismic activity over phases of the 11-year solar cycle. We have revealed a pattern in the distribution of seismic activity over latitudinal belts: the solar cycle phases, at which the main maximum of seismic activity occurs, increase with increasing latitude in both hemispheres. For some regions, the results may differ from the generalized results for Earth due to the influence of local geodynamic conditions during the destruction of the earth's crust. In middle latitudes, the maximum
\end{abstract}

number of earthquakes is shifted to the later phases of the solar cycle from west to east, which was not found for the northern regions. We discuss possible reasons for various manifestations of solar-terrestrial relationships for different regions, taking into account their different structure and geodynamic development modes. The presence of pronounced maxima of the seismic activity distribution over the 11-year solar cycle phases allows us to use them for refining the "time" parameter in the medium-term prediction of dangerous earthquakes.

Keywords: periodicity in seismic mode, solar activity, drift of Earth's core, asymmetry of the hemispheres, solar-terrestrial relations, geodynamics, factors of extraterrestrial effects, medium-term earthquake prediction.

\section{INTRODUCTION}

In recent decades, a question about the possible relation between Earth's seismicity and the 11-year solar cycle has been actively addressed [Lyubushin et al., 1998; Levin, 2006; Sidorenkov, 2009; Tyapkin, 2012]. Periodicities in the seismic regime of the Baikal Rift Zone (BRZ) have been observed by many researchers, and several harmonics including the 11-year one have been identified [Lyubushin et al., 1998; Dyad'kov, 2002; Levin, 2006; Levina, Ruzhich, 2010, 2016; Levina, Ruzhich, 2015; Ruzhich et al., 2018]. The most pronounced 11-year periodicity in the seismic regime of different regions of Earth is often attributed to the influence of changes in the level of solar activity. There is, however, an opinion about the absence of such a relation [Chipizubov, 2018]. There is no consensus of opinion on the distribution of seismic activity over solar cycle phases either. Below we discuss the causes of these differences and the possible nature of the 11-year periodicity. The solar cycle is known to last from 7 to 13 years, and it is asymmetric: the ascending branch (increasing Wolf numbers) is generally shorter than the descending one; hence, the choice of the reference point becomes significant. This paper shows the difference in the distribution of seismic activity over phases of the 11-year solar cycle for the entire planet, hemispheres, sectors, latitudinal belts, and individual regions. We focus on the analysis of additional information about cosmogenic factors affecting geodynamic processes, including seismotectonic destruction in the earth's crust.

\section{COMPUTING METHOD AND INITIAL DATA}

The epoch superposition method has been adopted: to determine the statistical relationship between two processes, corresponding series are first smoothed using the same time window, then it is calculated which phases of one process exhibit maximum values of parameters of another process, which are summed over a long period of time. For the calculations, we have used the catalog of earthquakes for the observation period from 1964 to 2018 with a magnitude $M \geq 5.0$ [Northern California Earthquake Data Center, https://ncedc.org/ncedc/ catalog-search.html] and the catalog of earthquakes in BRZ, provided by the Baikal Branch of the Geophysical Center of the Siberian Branch of the Russian Academy of Sciences (Irkutsk) [http://www.seis-bykl.ru]. As characteristics of seismic activity we considered series of the number of earthquakes and the total released seismic energy. To eliminate the effect of the annual cycle of Earth's revolution around the Sun, the series were smoothed using a time window of one year. Solar activity was described using Wolf numbers for the period from 1964 to 2018 and yearly average ones. We took the minimum moment of this parameter as the beginning of the cycle. The period considered contains five solar cycles of different duration $(12,10,10,13,11$ years). The average solar cycle duration is 11.2 years, therefore the smoothed series of Wolf numbers was approximated by the 11-year harmonic whose minimum 
was taken as the beginning of the next solar cycle. Next, for each earthquake we determined to which year of cycle it belonged. The number of events and their energy for the corresponding years were summed over all the five cycles.

\section{CALCULATION RESULTS}

The distribution of earthquakes and released seismic energy over phases of the 11-year solar cycle for the entire planet, Northern and Southern hemispheres is shown in Figure 1. We can see that for entire Earth the distribution of the released seismic energy (Figure 1, b) has two maxima: in the first and seventh years of the solar cycle; and the distribution of the number of earthquakes (Figure 1, a) has only one maximum, in the seventh year. Noteworthy is that the graphs for the Northern Hemisphere are virtually similar to those for Earth as a whole. As for the Southern Hemisphere, the main difference lies in the fact that the maximum of the released seismic energy occurs about one year earlier.

Let us now analyze the distribution of seismic activity over longitudinal hemispheres (Figure 2). Of course, the division into the Eastern and Western hemispheres is largely arbitrary: unlike the equator, the prime meridian has no physical meaning and is randomly chosen.

We can see (Figure 2) that the distribution for the Eastern Hemisphere shows a closer similarity to the distribution of seismic activity for Earth as a whole. In the Western Hemisphere, the main maximum of released seismic energy occurs earlier - in the fourth year of the solar cycle.

The next level of the analysis is latitudinal and lon- gitudinal belts. Latitudinal belts were taken of width $10^{\circ}$; longitudinal ones, $15^{\circ}$. For each belt we plotted distributions of the number of earthquakes and the released seismic energy over solar cycle phases. Then, from each phase we determined the solar cycle phase during which the main maximum of the corresponding parameter occurred. The result is presented in Figure 3. The graph itself (solid line) has a complex shape, but the trend line (dashed line), represented by the second degree polynomial, shows that the main maximum occurs later with increasing latitude both for the number of earthquakes $(a)$ and for their total energy $(b)$. No regularity has been revealed for longitudinal belts.

We turn now to the consideration of individual regions (Figure 4). It should be noted that the regions selected for analyzing seismic regimes radically differ from each other in existing regimes of seismotectonic degradation of the lithosphere. Graphs for each region (letter designations are the same as in Figure 4) are given in Figure 5: top six graphs (a) show the distribution of the number of earthquakes; bottom six graphs $(b)$ indicate the distribution of the released seismic energy over solar cycle phases. Vertically in each block, the graphs are in order of changing longitudes of the respective regions from west to east.

Parts of the Atlantic Rift (a), the Himalayan collision zone (b), and the Japanese subduction zone (c) are located approximately in one latitudinal range - from $20^{\circ}$ to $50^{\circ} \mathrm{N}$. Figure 5 shows that the main maxima of the number of earthquakes shift to later solar cycle phases from west to east.

For series of the total energy, this regularity can be observed only partially. Three other regions of interest -
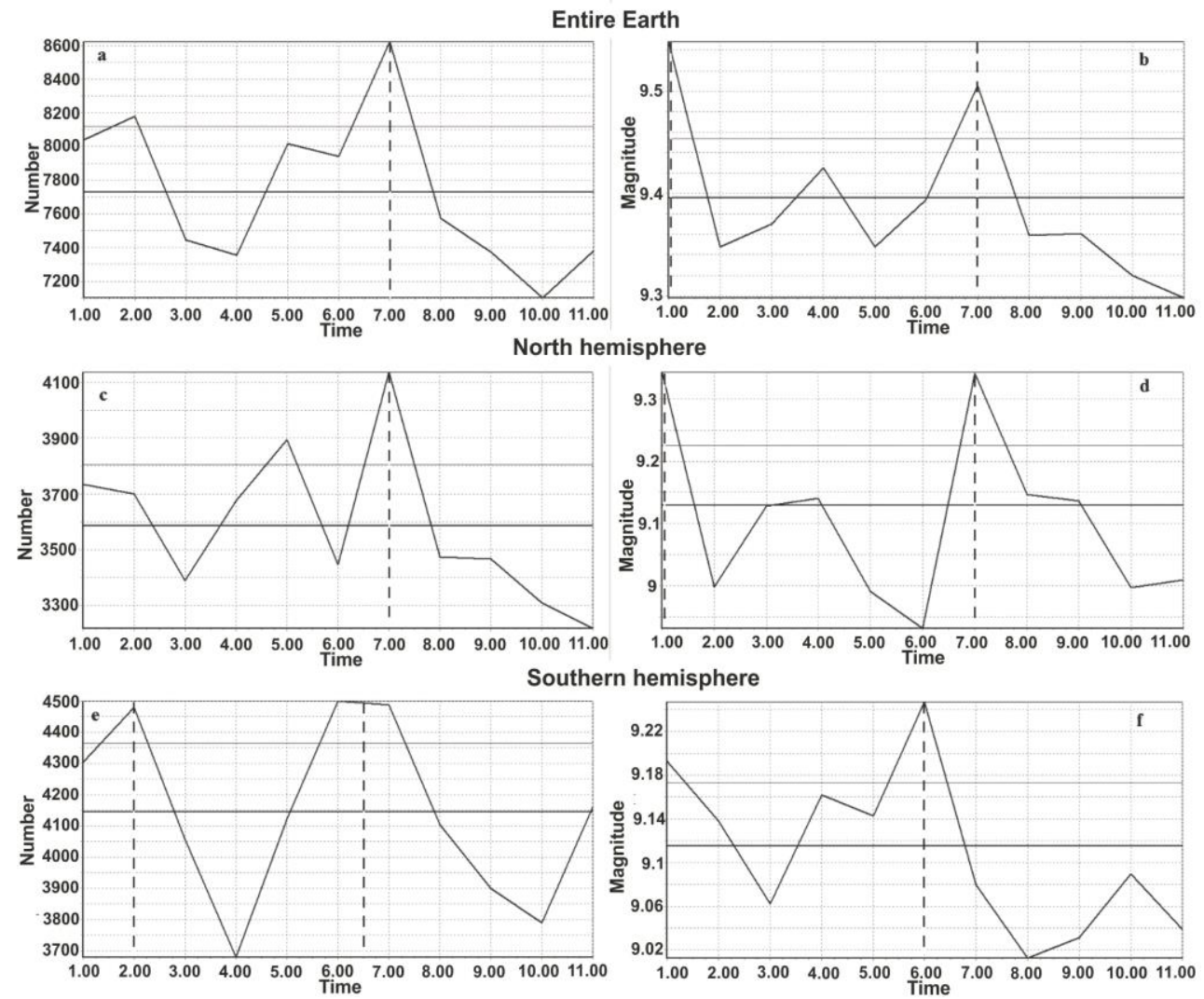

Figure 1. Distribution of the number of earthquakes $(a, c, e)$ and the released seismic energy $(b, d, f)$ for entire Earth $(a, b)$, Northern $(c, d)$ and Southern $(e, f)$ hemispheres over solar cycle phases. Along the X-axis is the time in years of the 11-year solar cycle. Dashed lines indicate the main maxima. The horizontal line is the mean value of the corresponding parameter 


\section{Entire Earth}
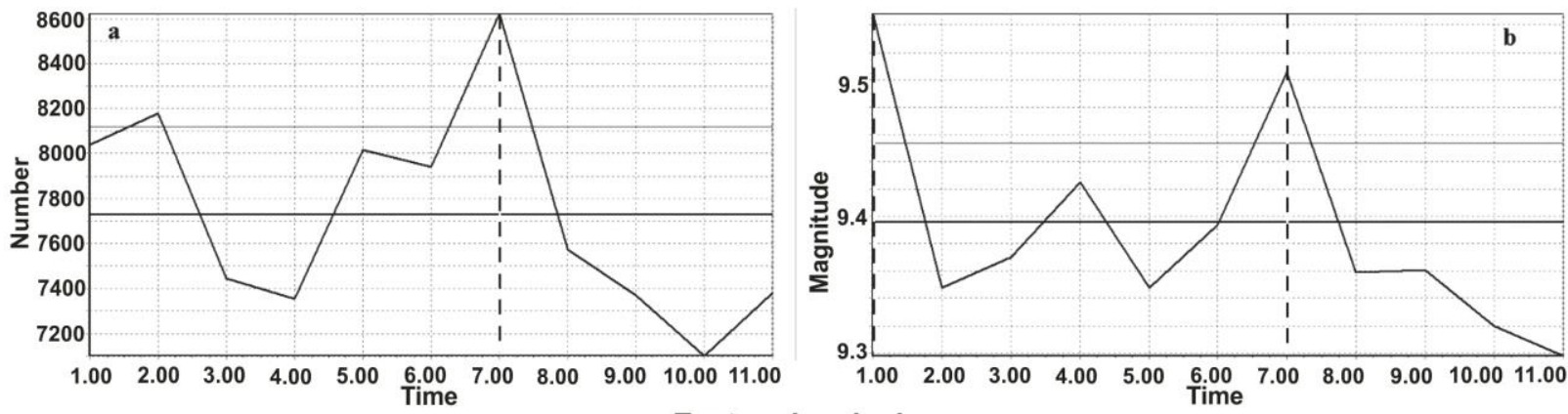

Eastern hemisphere
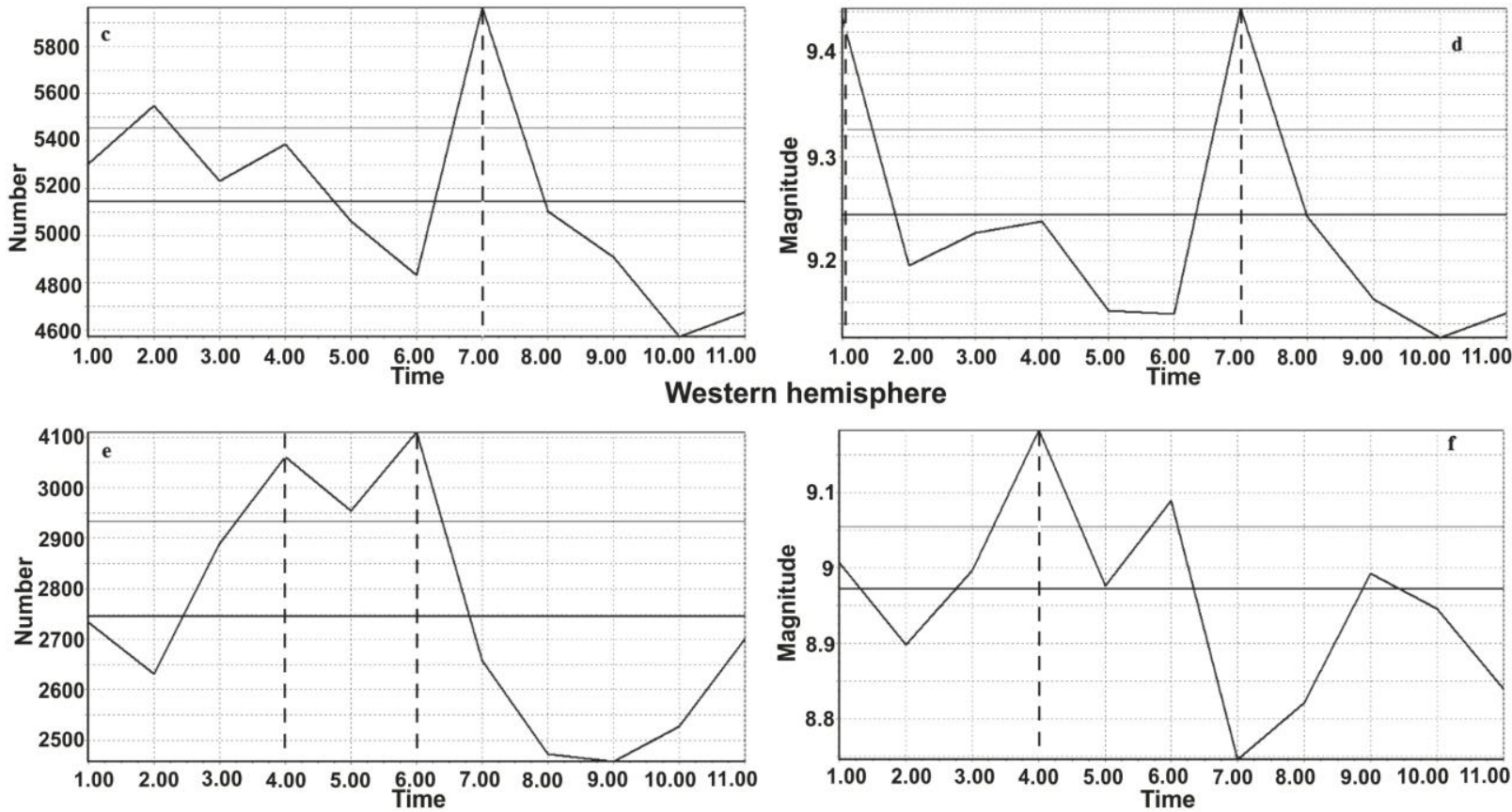

Figure 2. Distribution of the number of earthquakes $(a, c, e)$ and the released seismic energy $(b, d, f)$ for entire Earth $(a, b)$, Eastern $(c, d)$ and Western $(e, f)$ hemispheres over solar cycle phases. Along the X-axis is the time in years of the 11-year solar cycle. Dashed lines mark the main maxima
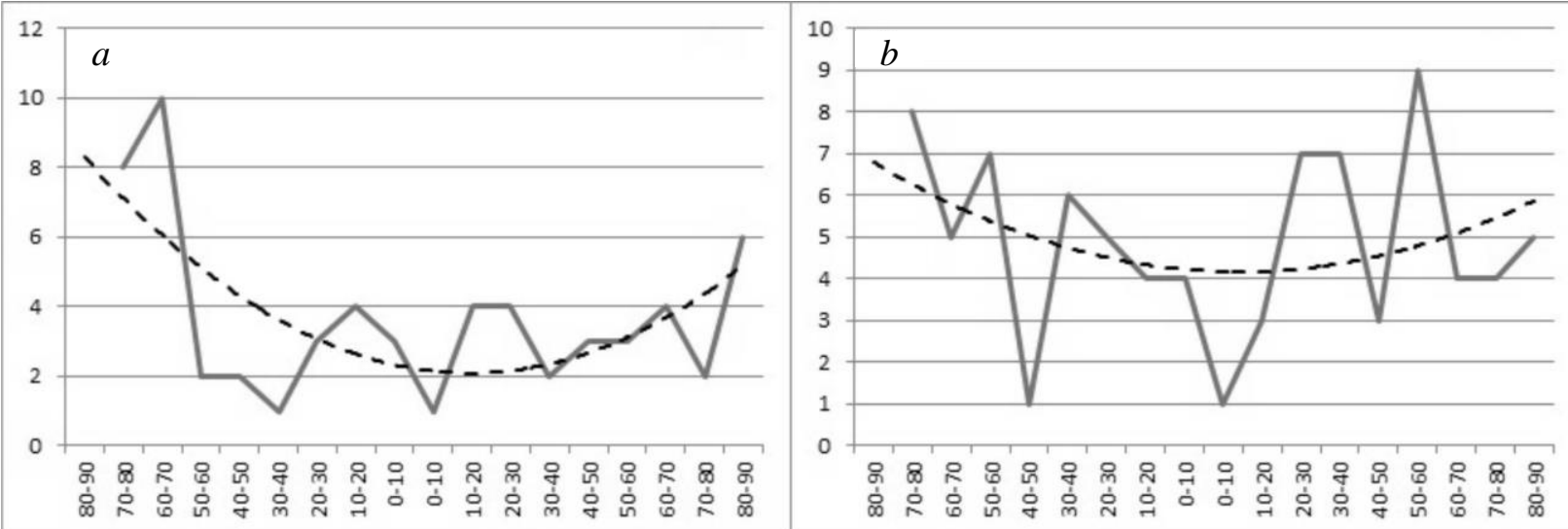

Figure 3. Distribution of the main maxima of the number of earthquakes $(a)$ and the released seismic energy $(b)$ in latitudinal belts of Earth over solar cycle phases (solid line). Along the $\mathrm{Y}$-axis is the time in years of the 11-year solar cycle; along the $\mathrm{X}$-axis are geographic coordinates of latitudinal belts; on the left is the Southern Hemisphere, on the right, the Northern Hemisphere. The dashed line shows a trend 


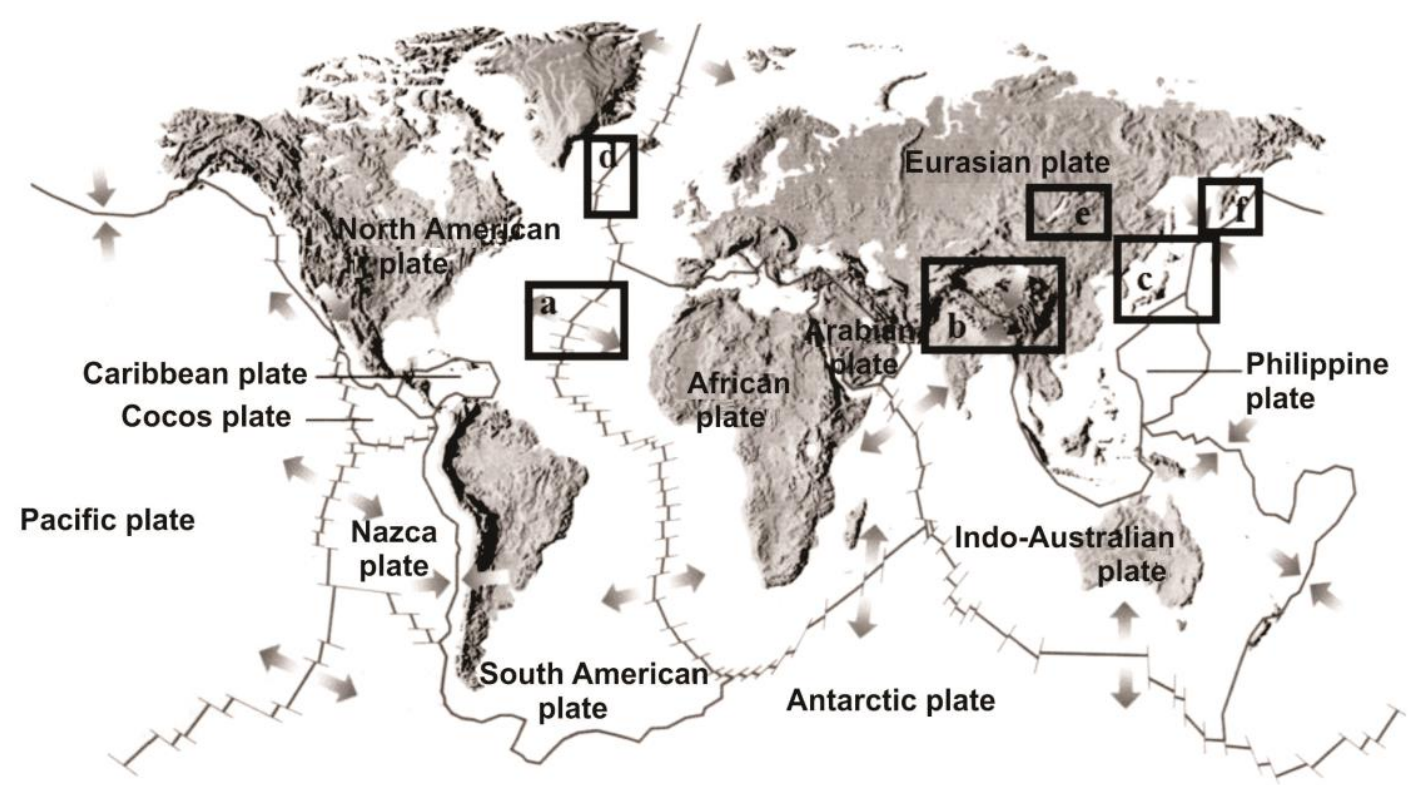

Figure 4. Location of regions considered (rectangles): parts of the Atlantic Rift (a), Himalayan collision zone (b), and Japanese subduction zone $(c)$; the North Atlantic Rift (d), BRZ (e), and the Kamchatka part of the subduction zone $(f)$

the North Atlantic Rift $(d)$, BRZ (e), and the Kamchatka part of the subduction zone $(f)$ - also have close latitudinal location - from $48^{\circ}$ to $65^{\circ} \mathrm{N}$. For them, no regularity has been found in the displacement of the main maxima in the longitudinal direction for series of the number of earthquakes. Noteworthy here is the similarity between the two groups of regions in the distribution of the total seismic energy: the main maxima of this parameter occur during the earlier solar cycle phase for the regions occupying the middle position in longitude $(b, e)$.

\section{DISCUSSION OF RESULTS AND THEIR INTERPRETATION}

The analysis of the results shows that for all the above regions we have identified the solar cycle phases during which the number of earthquakes or the total released seismic energy is maximum. The phases thus detected are, however, different for the globe (seventh year of the solar cycle) and individual hemispheres. In this case, the results of seismic dissipation in the lithosphere of the Northern and Eastern hemispheres almost coincide with those obtained for Earth as a whole, whereas in the Southern and Western hemispheres seismic activity maxima occur during the earlier phase. From this we can conclude that the planetary distribution of the current seismotectonic activity over phases of the 11-year solar cycle is largely determined by the northeastern sector of Earth. The asymmetry of the hemispheres we found manifests itself not only in the distribution of seismic activity over solar cycle phases but also in the distribution of earthquake regions over Earth's surface. Table 1 presents the distribution of the number of earthquakes with $M \geq 5$ over Earth's hemispheres.

We can see that $46 \%$ of earthquakes with $M \geq 5$ occur in the Northern Hemisphere and $55 \%$ in the Southern Hemisphere; the contribution of the Eastern Hemisphere is $67 \%$ versus $36 \%$ for the Western Hemisphere.
The distribution of the number of earthquakes over Earth's sectors is illustrated by the histogram in Figure 6. We can see that the contribution of the northeastern sector to the number of earthquakes with $M \geq 5$ is the greatest. The differences between seismic activity regimes in hemispheres and sectors in terms of geodynamics may be indirectly related to mantle flows, which, in turn, are triggered by the drift of Earth's core from its geometric center to the northeastern sector of the planet [Barkin, 2009; Goncharov et al., 2014].

We have statistically identified a feature in the distribution of seismic activity over latitudinal belts: the main maxima of seismic activity with increasing latitude occur during later and later phases in both hemispheres. No regularities in the distribution of seismic activity over longitudinal belts have been found.

The results of the calculations carried out for individual regions may differ from the results obtained for individual hemispheres of Earth as a whole. For the regions located in middle latitudes, there is a shift of the maximum number of earthquakes to later phases of the solar cycle in the direction from west to east, but we have not found such a regularity for northern regions with a latitude of $>50^{\circ}$.

Differences in the distribution of seismic activity over the latitudinal belts manifest themselves not only in its distribution over solar cycle phases but also in the location of epicenters of earthquakes on Earth's surface. Figure 7 shows that the maximum number of strong earthquakes with $M \geq 5$ occurs in the near-equatorial region, and also there is a local maximum at latitudes $30^{\circ}-50^{\circ}$ in the Northern Hemisphere, where the Alpine-Himalayan interplate collision zone is located.

The influence of cosmogenic factors on terrestrial processes is often estimated from solar activity, since this factor is easily represented in numerical form as a series of Wolf numbers. Nevertheless, there is still no clear understanding of the nature of this influence. One hypothesis is that the correlation of solar activity with 

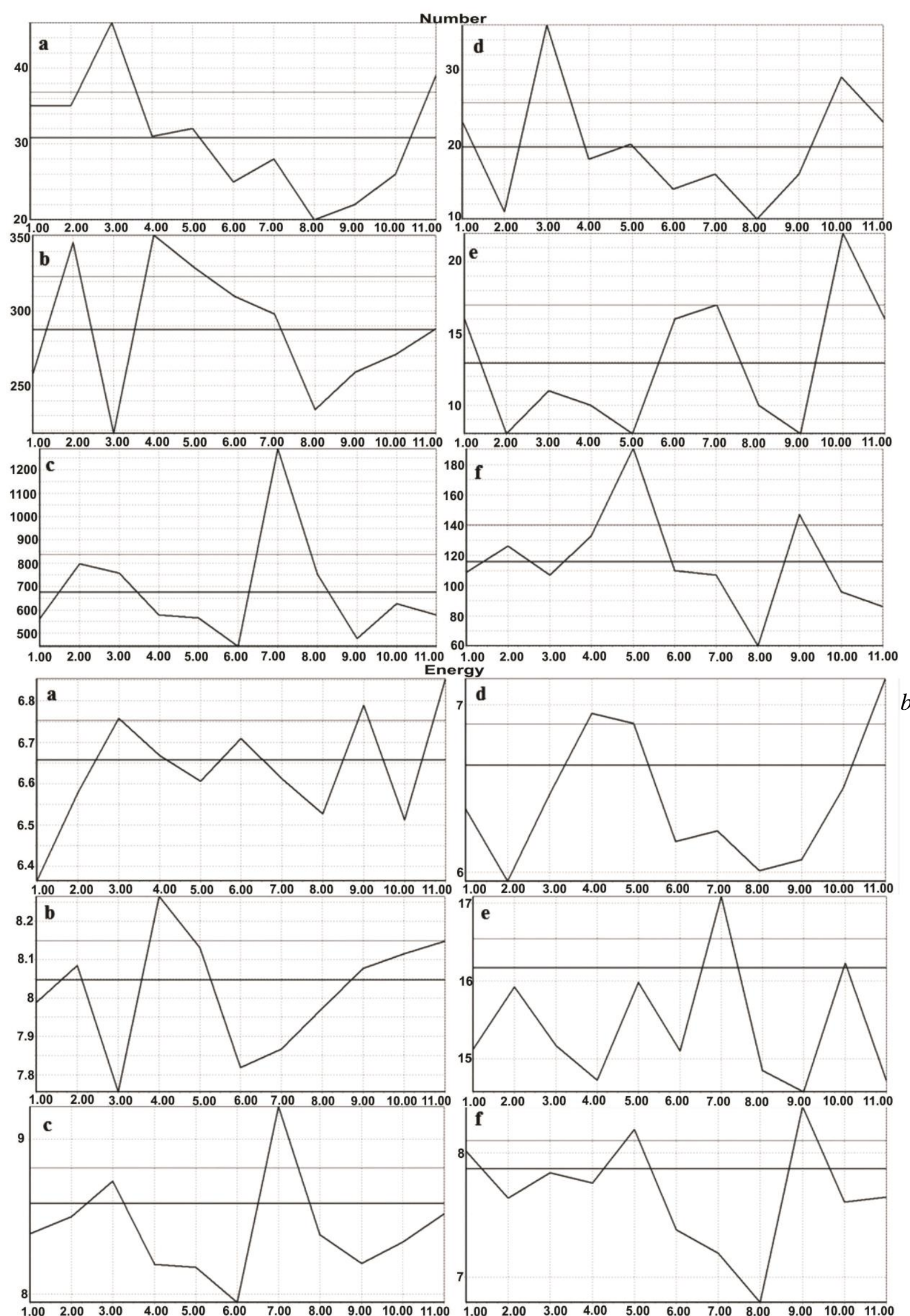

Figure 5. Distribution of the number of earthquakes $(a)$ and the released seismic energy $(b)$ for the regions designated by the corresponding letters in Figure 4. Along X-axes is the time in years of the 11-year solar cycle; Y-axes: $a$ - the number of events; $b$ - magnitude, except $e$ that shows classes (BRZ) 
Table 1 Distribution of the number of strong earthquakes with $M \geq 5$ over Earth's hemispheres

\begin{tabular}{|l|c|c|}
\hline \multirow{2}{*}{\multicolumn{1}{|c|}{ Region }} & \multicolumn{2}{c|}{$M \geq 5$} \\
\cline { 2 - 3 } & Number & $\%$ \\
\hline Entire Earth & 85016 & 100 \\
\hline Northern Hemisphere & 39444 & 46 \\
\hline Southern Hemisphere & 45583 & 55 \\
\hline Eastern Hemisphere & 56595 & 67 \\
\hline Western Hemisphere & 30194 & 36 \\
\hline
\end{tabular}

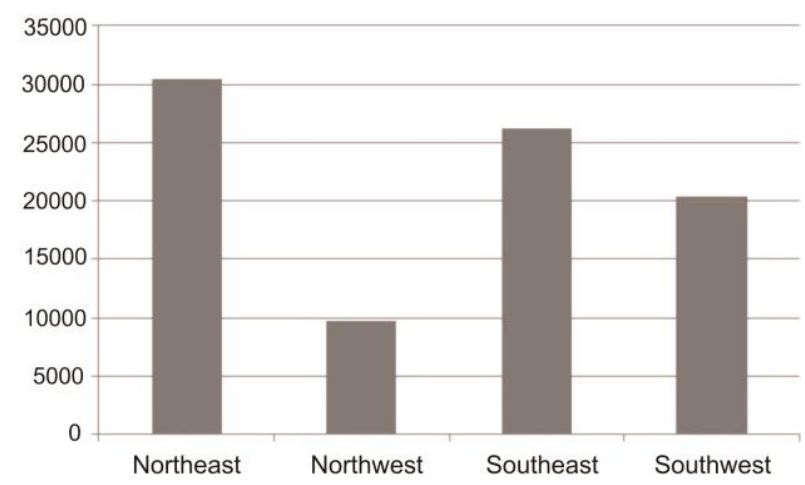

Figure 6. Distribution of the number of earthquakes with $M \geq 5$ over Earth's sectors

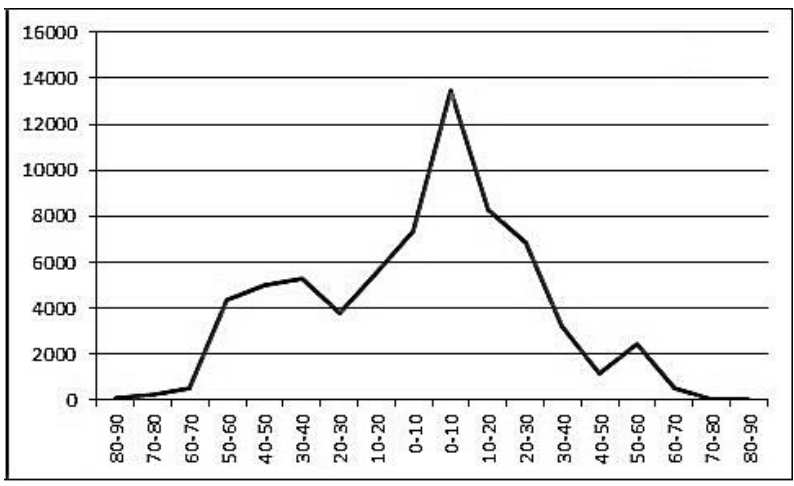

Figure 7. Distribution of the number of earthquakes over Earth's latitudinal belts. To the left on the X-axis are latitudes of the Northern Hemisphere; and to the right, of the Southern one

seismic activity of Earth may be attributed to the influence of the same factor on both the processes.

Avsyuk [1996] has shown that a change in the total tidal force affecting the Sun (in the Sun - Jupiter Saturnsystem) corresponds to a change in solar activity considered over the period from 1800 to 1980 . By the total tidal force is meant here the disturbing effect caused by the rotation of the Sun around the barycentre of the solar system. The above cosmogenic factors may be capable of initiating short-period variations with similar duration in Earth's seismic regime.

We are well aware of that too short series of seismic data used in the calculations do not exclude the occurrence of random coincidences or, on the contrary, omit actual kinds of influence of extraterrestrial factors on seismotectonic deformation. From the standpoint of planetary geophysics, it has been shown that solar activity only partially contributes to the formation of solarterrestrial relations [Nagovitsin, 2012; Smolkov, 2018].
Note that geodynamic effects of extraterrestrial impacts effectively manifest themselves as responses only for those areas of our planet, where in zones of interplate and intraplate faults there is an unstable geomechanical balance. Despite the quasi-regularity of the extraterrestrial impacts, significant seismic events initiated by a triggering mechanism not always occur in faults, therefore their identification becomes more reliable in the analysis of sufficiently long data series by statistical methods. In such calculations, we should also take into account possible delays of responses of geomechanical systems to extraterrestrial dynamic effects, which complicate their detection [Ruzhich, 1997].

From the standpoint of geodynamics it is useful to compare the energy of gravitational and thermal fields. Table 2 presents data on the energy balance of Earth and power of different geodynamic processes [Barkin, 2013]. We can see that their total power is only slightly higher than the power of volcanic processes, but by three orders of magnitude lower than the power of heat convection and by four-five orders of magnitude lower than the power of dissipation both of the energy of mantle processes and of the total released energy of oscillatory motions of Earth's core and viscoelastic deformations in the mantle. Due to the lack of knowledge, it is still very difficult to estimate the energy of the terrestrial gravitational eigenfield and the energy of the gravitational effect of the Sun and planets of the solar system.

In geosciences, misconceptions are often encountered which underestimate the energy contribution of the gravitational field of our planet and particularly of the solar system to geodynamics as compared to the contribution of the thermal field of Earth. At the same time, geologists ignore frictional processes that occur when slipping between geospheres, lead to the melting of huge volumes of rocks, to the occurrence of magma pockets, mantle currents, and channels of penetration of huge volumes of melts of mantle matter in the form of plumes, facilitated by gravitational differentiation, into the bottom of the lithosphere [Stothers, 1993; Bakirov, 2007; Dobretsov, Turkina, 2015]. A huge amount of energy of impacts of the gravitational field of the Sun and planets of the solar system on Earth usually goes unnoticed [Smolkov, Barkin, 2014].

Many experts do not still understand causes, mechanisms, and consequences of the extraterrestrial impacts on the form of the geoid (Figure 8), including causes and characteristics of the drift of the inner core, manifestations of convection currents in the mantle, emergence of superplumes, destruction of the lithospheric shell, as well as changes in paths of motion of lithospheric plates and interplate interactions. Figure 8 shows the detected drift of Earth's mass center to the northeastern sector. The very fact of the core motion has been found out from DORIS system imaging data [Zotov et al., 2009]. Many geodynamic processes can be considered as consequences of the fundamental phenomenon - accelerated movements of the core mass center relative to the mantle mass center.

Geodynamic consequences of the centuries-old drift 
of Earth's mass center to its northeastern sector revealed themselves in changes of the form of the geoid. Near the south pole, the concavity appeared; near the north pole, the bulge. According to the ideas discussed in [Goncharov et al., 2014], the drift of Earth's core in the said direction gave rise to a submeridional current in the mantle and to the northeastward compression of the earth's crust extended over Earth. From the geological viewpoint, the observed shape of Earth can be considered as clear evidence of deformation processes in the upper shell of the planet, initiated by stepwise displacements of its core and mantle disturbances. Another example confirming the important role of the compression of the earth's crust in geodynamics is the widespread occurrence of thrusts and reverse-strike faults in East Siberia,

Table 2

Earth energy budget

and power of geodynamic processes

\begin{tabular}{|l|l|}
\hline Power of seismic events & $3 \cdot 10^{10} \mathrm{~W}$ \\
\hline Power of volcanic events & $10^{10} \mathrm{~W}$ \\
\hline Power of thermal convection & $10^{13} \mathrm{~W}$ \\
\hline Heat flow & $(4.4-4.8) \cdot 10^{13} \mathrm{~W}$ \\
\hline Tides & $4 \cdot 10^{11} \mathrm{~W}$ \\
\hline $\begin{array}{l}\text { Dissipation power due to os- } \\
\text { cillations of the core and vis- } \\
\text { coelastic deformations of the } \\
\text { mantle }\end{array}$ & $3.38 \cdot 10^{14} \mathrm{~W}$ \\
\hline $\begin{array}{l}\text { Total power of energy dissipa- } \\
\text { tion in the Earth mantle }\end{array}$ & $10^{14}-10^{15} \mathrm{~W}$ \\
\hline
\end{tabular}

including BRZ. According to the estimated age of thrust-fractured Miocene-Quaternary basalt dikes, the horizontal compression of the earth's crust in the northeast direction occurred during orthogonal riftogenic extension of the earth's crust relative to the compression axis [Ruzhich et al. 1972; Ruzhich, 1997]. In the study of solar-terrestrial relations, in terms of the core drift and its related submeridional convection in the mantle we can find a logical explanation of other geodynamic processes emerging in plate tectonics.

According to the available geological information, e.g., [Letnikov, 2001; Rodkin, Rundkvist, 2017], an additional and still little-known factor acting within solar-terrestrial relations and affecting many terrestrial physicochemical processes may be the planetary thermogravity process, which manifests itself in the form of high-speed transfer of huge volumes of mineral matter from the outer boundary of Earth's core to the upper layers of the mantle and to the lithosphere by gassaturated lightweight fluids. Pulsed propagation of fluids rapid in geological terms naturally stimulates viscoplastic deformation processes in the lithosphere and an episodic accelerated decrease in shear resistance in fault zones. With such a mechanism, frictional instability may occur in segments of fault zones, which, along with deformation waves, including tidal ones, promotes quasiperiodic activation of trigger-type seismic processes

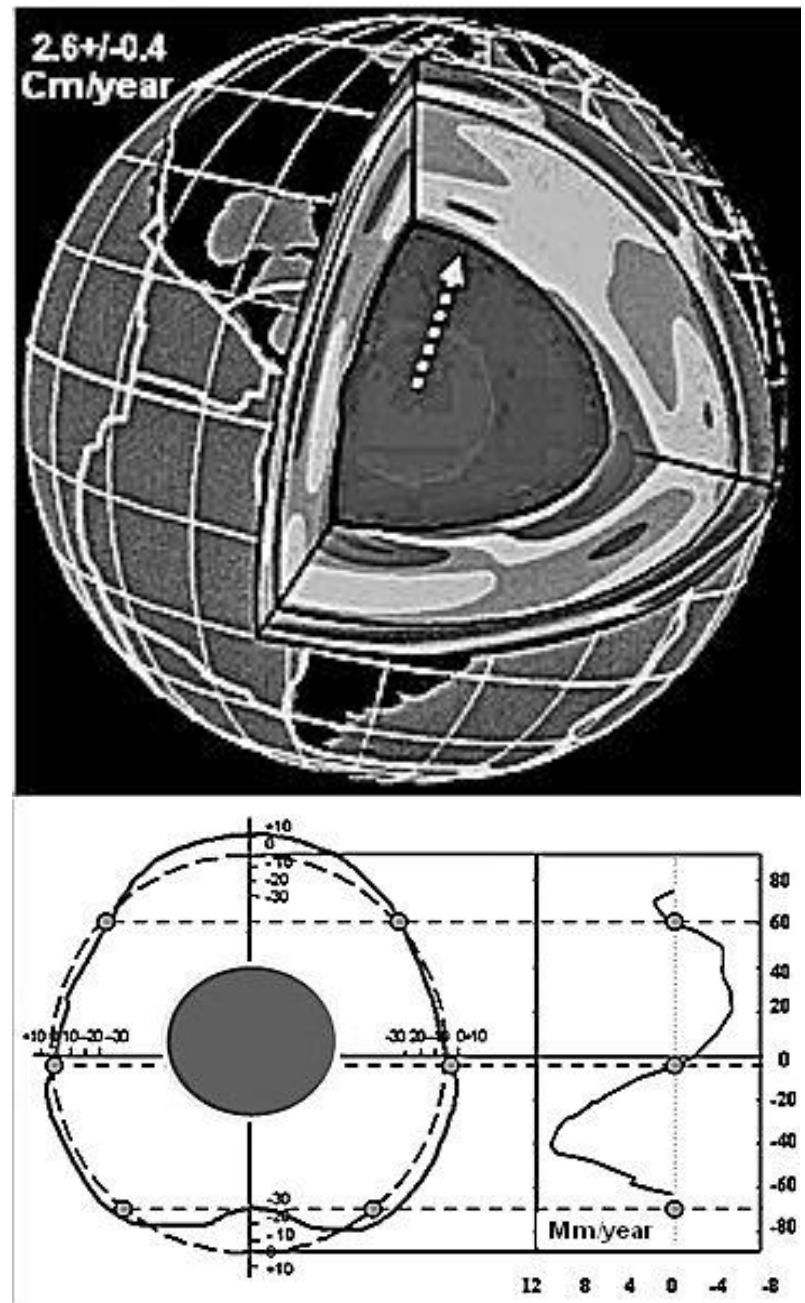

Figure 8. The Earth mantle (top), the arrow indicates the direction (northeastward) of the drift of Earth's mass center for the period from 1993 to 2007 [Zotov et al,. 2009]; the drift velocity is shown in the top left corner. The form of the geoid and its changes (bottom) observed in the recent epoch according to [Barkin, 2002; Khain, Khalilov, 2009]

[Levina, Ruzhich, 2010]. The interaction between the gravitational field and the thermal field of Earth continuously manifests itself through the activity of endogenous processes, such as the drift of the mass center, physicochemical transformations of rocks, convective currents in the mantle, magmatism, emergence of plumes, and through periodicities in seismotectonic degradation, including the 11-year one.

The kinetic energy contribution, associated with the effect of variations in the rotational and orbital revolution of Earth, to endogenous processes is also significant [Bakirov, 2007; Song, Richards, 1996; Raman, 2011]. This energy undoubtedly affects the modes of release of the elastic seismic energy during deformation and destruction of the lithospheric shell. Levin and Sasorova [2012] have observed a statistically significant similarity between global distributions of seismic events for Earth and the Moon, which has no such a thermal energy source as the hot core. 


\section{CONCLUSION}

We have demonstrated the presence of statistically significant maxima in the distribution of seismic activity over phases of the 11-year solar cycle, which were identified by the superposed epoch method. The ambiguous results obtained by different authors when studying the periodicity in the seismic regime of Earth can be explained by complex combinations of cosmogenic factors affecting the geodynamics of the planet as a whole and its individual regions.

The presence of clear maxima in the distribution of seismic activity over solar cycle phases allows us to identify the periods when the probability of an increase in the number of earthquakes or the occurrence of a strong earthquake significantly increases. Using the Baikal Rift Zone as an example, we have confirmed the significance of this factor in the medium-term earthquake prediction [Ruzhich, 1997; Ruzhich et al., 2018].

We believe that the detailed study of the relationship between the 11-year solar cycle and the seismic activity regime can not only estimate the influence of extraterrestrial factors on the processes occurring on our planet but also provide reasoned explanations of many phenomena in geology and geodynamics.

The work was performed under base project No. 0346-2019-0007 «Tectonophysics of current geodynamic processes in the lithosphere of Central Asia as a basis for the prediction of natural emergencies".

\section{REFERENCES}

Avsyuk Yu.N. Prilivnye sily i prirodnye protsessy [Tidal Forces and Natural Processes]. Moscow, IPE RAS Publ., 1996, 188 p. (In Russian).

Bakirov A.B. The most important Earth's structures and sources of energy of geodynamic processes. Fundamental'nye problemy geotektoniki: materialy coveshchaniya [Proc. XL Tectonic Workshop "Fundamental Problems of Geotectonic"] Vol. 1. Moscow, GEOS Publ., 2007, pp. 43-45. (In Russian).

Barkin Yu.V. Interpretation of endogenous activity of planets and their satellites, and its cyclicity. Trans. of Earth's Sci. Section of RANS. Moscow, VINITI Publ., 2002, pp. 45-97. (In Russian).

Barkin Yu.V. Relative displacements of Earth's core and mantle, and their role in a seismic process. Mezhdunarodnaya konferentsya "Geologiya: istoriya, teoriya, praktika" [International Conference "Geology: History, Theory, Practice"] Moscow, State Geological Museum Publ., 2009, pp. 20-24. (In Russian).

Barkin Yu.V. Synchronous jumps in processes and phenomena on Earth, Moon and Sun in 1997-1998, and their common mechanism. Geologiya morei i okeanov: Trudy XX Mezdunarodnoi nauchnoi konferetsii (shkoly) po morskoi geologii [Geology of Seas and Oceans. Proc. XX International Scientific Conference (School) on Sea Geology]. Vol. 5. Moscow, GEOS Publ., 2013, pp. 21-25. (In Russian).

Chipizubov A.V. On prediction of changes in Earth's seismicity from variability of solar activity and other geonomic processes. XII Russian-Mongolian International Conference "Solar-Terrestrial Relations and Geodynamics of the Baikal-Mongolia Region": Abstracts. Irkutsk, October 2-4, 2018, p. 25. (In Russian).

Dobretsov N.L., Turkina O.M. Early Precambrian Earth history: the role of plate and plum tectonics and extraterrestrial controls. Geologiya i geofizika [Geology and Geophys.]. Geology and Geophys. 2015, vol. 56, no. 7, pp. 1250-1274. (In Russian). DOI: 10.15372/GiG20150702.
Dyad'kov P.G. Periodicities in seismic regime and tension changes in Baikal Rift Zone crust: correlation with 11-year solar cyclicity and seasonal variations of Lake Baikal. Atlas vremennykh variatsii prirodnykh, antropogennykh $i$ sotsial'nykh protsessov [Atlas of Time Variations in Natural, Anthropogenic and Social Processes]. Vol. 3. Moscow, Yanus-K Publ., 2002, pp. 251-254. (In Russian).

Goncharov M.A., Raznitsin Yu.N., Barkin Yu.V. Northern component in continental drift in Phanerozoic: structural consequences and possible origin. Doklady Akademii nauk [Doklady Physics]. 2014, vol. 455, no. 5, pp. 550-552. (In Russian). DOI: 10.7868/S0869565214110176.

Khain V.E., Khalilov E.N. Tsiklichnoct' geodinamicheskikh protsessov: eyo vozmozhnaya priroda [Cyclicity of Geodynamic Processes: its Possible Origin]. Moscow, Nauchnyi mir Publ., 2009, 520 p. (In Russian).

Levin B.W. On the nature of some periodic changes in Earth's seismic regime. Vestnik DVO RAN [Vestnik of the Far East Branch of the Russian Academy of Sciences]. 2006, no. 1, pp. 51-58. (In Russian).

Levin B.W., Sasorova E.V. Seismotectonics and Earth tides. Russian Journal of Pacific Geology. 2012, vol. 6, no. 1, pp. 70-77. DOI: 10.1134/S1819714012010095.

Levina E.A., Ruzhich V.V. Earthquake migration as a manifestation of wave deformations of the Earth's crust. Vserossiiskii seminar-coveshchanie "Triggernye effekty $v$ geosistemakh": trudy [Proc. the Russian National SeminarMeeting "Trigger Effects in Geosystems"]. Moscow, GEOS Publ., 2010, pp. 71-78. (In Russian).

Levina E.A., Ruzhich V.V. The seismicity migration study based on space-time diagrams. Geodynamics and Tectonophysics. 2015. vol. 6, iss. 2, pp. 225-240. DOI: 10.5800/GT2015-6-2-0178.

Levina E.A., Ruzhich V.V. Manifestation of 11-year periodicity in seismomigration processes of Earth's rift systems. Trudy III Vserossiiskogo coveshchaniya u II Vserossiiskoi molodezhnoi shkoly po sovremennoi geodinamike "Sovremennaya geodinamika Tsentral'noi Azii $i$ opasnye prirodnye protsessy" [Proc III Russian National Meeting and II Young Scientist's School on Present-Day Geodynamics "Present-Day Geodynamics of Central Asia and Hazardous Natural Processes: Results of Studies at Quantative Basis"]. Irkutsk, IEC SB RAS Publ., 2016, pp. 269-272. (In Russian).

Letnikov F.A. Super-deep fluid Earth's systems and oregenesis problems. Geologiya rudnykh mestorozhdenii [Geology of Ore Deposits]. 2001, vol. 43, no. 4, pp. 291-307. (In Russian).

Lyubushin A.A., Pisarenko V.F., Ruzhich V.V., Buddo V.Yu. Extraction of periodicities in seismic regime. Vulkanologiya i seismologiya [Volcanology and Seismology]. 1998, no. 1, pp. 62-76. (In Russian).

Nagovitsin Yu.A. Solar activity and solar-terrestrial relations at different time scales. Vserossiiskaya konferentsya "Solnechnaya aktivnost' i priroda global'nykh i regional'nykh klimaticheskikh izmenenii" [Russian National Conference "Solar Activity and Nature of Global and Regional Changes"]. Abstracts. Irkutsk, June 19-22, 2012, p. 20. (In Russian).

Northern California Earthquake Data Center. URL: http://www.ncedc.org. (accessed May 20, 2019).

Raman K. Space weather - Sun Earth - relations. Intern. J. Astron. Astrophys. 2011, no. 1. pp. 10-14. DOI: 10.4236/ijaa.2011.11003.

Rodkin M.V., Rundkvist D.V. Geoflyuidogeodinamika. Prilozhenie $k$ seismologii, tektonike, protsessam rudo- $i$ neftegeneza [Geofluid Geodynamics. Application to Seismology, Tectonics, and Processes of Ore and Oil Genesis]. Dolgoprudny, Intellekt Publ., 2017, 288 p. (In Russian).

Ruzhich V.V. Seismotektonicheskaya destruktsiya $v$ zem- 
noi kore Baikal'skoi riftovoi zony [Seismotectonic destruction in the Earth's crust of Baikal Rift Zone]. Novosibirsk, SB RAS Publ., 1997, 144 p. (In Russian).

Ruzhich V.V., Sherman S.I., Tarasevich S.I. New data on overthrusts in south-western flank of Baikal Rift Zone. Doklady Akademii nauk [Doklady Physics]. 1972, vol. 205, no. 4, pp. 920-924. (In Russian).

Ruzhich V.V., Levina Ye.A., Ponomareva E.I. Availability and problems of the earthquake prediction (on an example of the Baikal rift). Mezhdunarodnaya yubileinaya nauchnaya konferetsiya "Vozdeistvie vneshnikh polei na seismicheskii rezhim i monitoring ikh proyavlenii" [International anniversary scientific conference "Effect of external fields on seismic regime and monitoring of their manifestations]: Abstracts. Bishkek, Kirghizia, NS RAN, July 3-7, 2018.

Sidorenkov N.S. The Interaction Between Earth's Rotation and Geophysical Processes. Weinheim, WILEY-VCH Verlag $\mathrm{GmbH}$ and Co. KGaA, 2009, 305 p. DOI: 10.1002/ 9783527627721 .

Smolkov G.Ya. The natural changes of solar-terrestrial relations. Adv. Res. Astrophys. 2018, vol. 3, no. 4, pp. 205-217. DOI: 10.22606/adap.2018.34001.

Smolkov G.Ya., Barkin Yu.V. To the systemic and interdisciplinary research into solar-terrestrial relationships. Kollokvium "Kosmicheskie factory evolutsii biosfery $i$ geosfery: trudy [Proc. Colloquium "Cosmic Factors of Biosphere and Geosphere Evolution"]. Moscow, May 21-23, 2014. S.
Petersburg, VVM Publ., 2014, p. 162. (In Russian).

Song X., Richards P.G. Seismological evidence for differential rotation of the Earth's inner core. Nature. 1996, vol. 382, pp. 221-224. DOI: $10.1038 / 382221 \mathrm{a} 0$.

Stothers R.B. Hot spot and Sun spot: surface of deep mantle convection in the Earth and Sun. Earth and Planetary Sci. Lett. 1993, vol. 116, pp. 62-69. DOI: 10.1016/0012821X(93)90041-7.

Tyapkin K.F. Change in rotation axis position in the Earth's body: origin, mechanism, and use for interpretation of global tectonic processes in the Earth's crust. Geofizicheskii Zhurnal [Geophys. J.]. 2012, vol. 34, no. 6, pp. 91-100. (In Russian).

Zotov L.V., Barkin Yu.V., Lubushin A.A. Geocenter motion and its geodynamical content. Space Geodynamics and Modeling of the Global Geodynamic Processes. Novosibirsk, Russian Federation, 22-26 September, 2008. Novosibirsk, Academic Publ. House "Geo", 2009, pp. 98-101.

URL: http://www.seis-bykl.ru (accessed May 20, 2019).

How to cite this article

Ruzhich V.V., Levina E.A. Features of distribution of seismic activity in different regions of Earth over phases of the 11-year solar cycle. Solar-Terrestrial Physics. 2020. Vol. 6. Iss 1. P.93-101. DOI: $10.12737 /$ stp-60120211. 